Manal A. Sultan

BDS, MSc (Assist Lect)

\section{The Effect Of Light Curing Intensity On Fluoride Release From Composite Resin}

\author{
Department of Conservative Dentistry \\ College of Dentistry, University of Mosul
}

\begin{abstract}
Aims: To find the effect of light cure intensity on polymerization of light cured composite resin(Tetric and Kerr composite resin). Which affects the amount of fluoride release from (light cure) composite resin. Materials and methods: Two types of light cure composite resins material (Tetric ceram and Kerr are used in this study, three groups of samples were made from each type of material used each group contain 10 samples which are cured by light cured device with different intensity of light cure.The first group of samples were cured by light the intensity of the light cure was $170 \mathrm{Mw} / \mathrm{cm} 2$. The second group of samples were cured by the intensity of $300 \mathrm{Mw} / \mathrm{cm} 2$, third group of samples were cured at the intensity of $470 \mathrm{Mw} / \mathrm{cm} 2$. Results: The amount of fluoride released from all samples were determined in (milli volt)then convert to ppm(part per million).The amount of fluoride release in to deionized water from materials at the high intensity were less from the amount of the fluoride release from the materials that cured at low intensity. Conclusions: The amount of the fluoride from the light cured composite resins material which cured at the high intensity is less than the amount of the fluoride released from light cured composite resin at low intensity. Which means that the intensity of light cure will affecting the amount of the fluoride release from light cured composite resin materials.
\end{abstract}

Key words: composite resin, fluoride release, light cure intensity.

Sultan M A. The effect of light curing intensity On fluoride release from composite resin. Al-Rafidain Dent J. 2009;9(2): 232 - 237.

Received: 13 /4 / $2008 \quad$ Sent to Referees: 14 /4 / 2008 Accepted for Publication: 22 /6 / 2008

\section{INTRODUCTION}

Because fluoride is an affective cariostatic agent many dental materials have been designed to provide fluoride to the oral environment ${ }^{(1-3)}$

It has been hopped that long-lasting timed released materials such as composite resin materials could provide suffient amount of fluoride at the site of the restoration to prevent further demineralization and to assist in remineralization ${ }^{(4-6)}$.

In recent years the use of low power densities has become wide spread in clinical practice as several studies have shown that the use of continues low intensity curing routines, as well as those characterized by reduced power density at the initial seconds, may lead to significant reduction in micro leakage and gap formation in composite restoration ${ }^{(7-8)}$.

Reduced power densities result in lower polymerization rates, allowing more time for the composite to flow before gelation $^{(9-10)}$.

It has been hypothesized that low power densities would generated small number of free radicals resulting in amore linear polyenric structure with lower cross linking density, as evidenced by reduced glass transition temperature and increase susceptibility to ethanol degradation other studies have shown that the use of continuous low-intensity photo activation did not seen to affect flexural strength ${ }^{(11-12)}$.

Fracture toughness or elastic modulus of Bis GMA- based materials compared to high intensity photo activation, given that energy density delivered was similar ${ }^{(13-14)}$.

Material and Method: The materials used in this study are: Herculite XR Resin composite and Tetric ceram.

The other accessories materials are: Sodium fluoride, Glecialacetic acid, Sodium chloride, Sodium citrate, Sodium Hyproxide (Seelze-Hannover). 


\section{MATERIALS AND METHODS}

Sixty samples were prepared, 30 samples for each types of materials used group I Tetric ceram composite resin and group II Kerr Composite resin.

Each sample is in the shape of $(10 \mathrm{~mm}$ diameter and $2.5 \mathrm{~mm}$ depth). By the use of we glass slides used to compress the materials, astainlessteel wire incorporated in to each disk sample to be served as an attachment.

All materials were then light cured by the use of Light curing conventional QTH, the curing was in four perpendicular points for each surfaces of the disk and for $40 \mathrm{sec}$ for each sides.

The intensity of the light cure was different for each 10 disk sample of each type of the materials used.

The first ten samples were cured by the light cure (QTH) and by the use of manual intensity changeable device we change the intensity to the $470 \mathrm{Mw} / \mathrm{cm}^{2}$.

The second ten samples were cured by the light cure at the intensity $300 \mathrm{Mw} / \mathrm{cm}^{2}$, the third ten samples were cured by the intensity $170 \mathrm{Mw} / \mathrm{cm}^{2}$.

After curing, the disk samples were removed from their molds, and suspended in to apoly athelen test tubes according to their groups.

Each test tube contain $3 \mathrm{ml}$ of deionized water after that the groups of sample were placed in an incubator at $37 \mathrm{C}^{\circ}$ for the first 24 hour.

Then after the first 24 hours we removed the samples from the incubator and we poured the water from the test tube from each sample to another test tube and we added a new quantity of deionized water to the sample and return them to the incubator.
The deionized water in which the sample was released fluoride in it we buffered it by the used of (TISAB) $(3 \mathrm{ml})^{(15)}$ for each sample which is the same amount of the deionized water which previously in the test tube .

By the use of fluoride ion specific electrode F1052 radiometer AIS (Emdrapuej 72 DK 2400 Copenhagen NV Denmark)

We measured the amount of the fluoride released. The measurements were assigned under the first day. The measurements first were made in MV(milli volt) then it were changed into PPM (part per million) by the use of the standard solution $^{(16)}$.

\section{Standard solution preparation:}

The standard solutions was prepared according to the dilution low for solutions. It is necessary to prepare a diluter solution of a substance by concentration (but containing the same amount of solution) are related to each other in the following manner:

Amount of solution $1=$ volume $1 \times$ concentration 1

Amount of solution $2=$ volume $2 \times$ concen tration 2

This means that the volume (expressed as $\mathrm{ml}$ ) and the concentration expressed as molarity $(\mathrm{m})$ of the two solutions is related as:

$\mathrm{Ml} 1 \times \mathrm{ml} 1=\mathrm{Ml} 2 \times \mathrm{ml} 2$

Molarity can mean either moles per liter or mill moles per milliliter, since $\mathrm{Ml} \times$ $\mathrm{m}=$ millimoles. The number of millimoles in a solution does not change when a solvent is added ${ }^{(16)}$.

According to this low we prepare the standard solution of fluoride $(\mathrm{NaF})$ in part permillion (ppm) as following:

$$
\begin{aligned}
& \text { ppm } 100=\frac{\mathrm{Wt}}{250} \times 10^{6} \\
& \text { where : } \\
& \mathrm{wt}=\frac{100 \times 250}{10^{6}}=25 \times 10^{-3} 0.025 \mathrm{mg}
\end{aligned}
$$


This (0.025) $\mathrm{gm}$ is to be solved in $250 \mathrm{ml}$ of deionized water in order to obtain a solution with concentration $100 \mathrm{pp}$ of fluoride $(\mathrm{NaF})$. Then the other standard solution also prepared in the same way with different concentrations from the original solution which was prepared. The concentration of the standard solutions are:
(10-100 with ten increment and 5, 1, 0.5, $0.01,0.05) \mathrm{ppm}$. After measuring these different concentrations of fluoride by radiometer A/S (EMRUPUSE 72 DK-2400 Copenhagen NU Denmark) with the fluoride ion selective electrode a curve drawn for the fluoride in ppm and $\mathrm{mv}$ which is obtained from the device for each concentration, as shown in Figure (1).

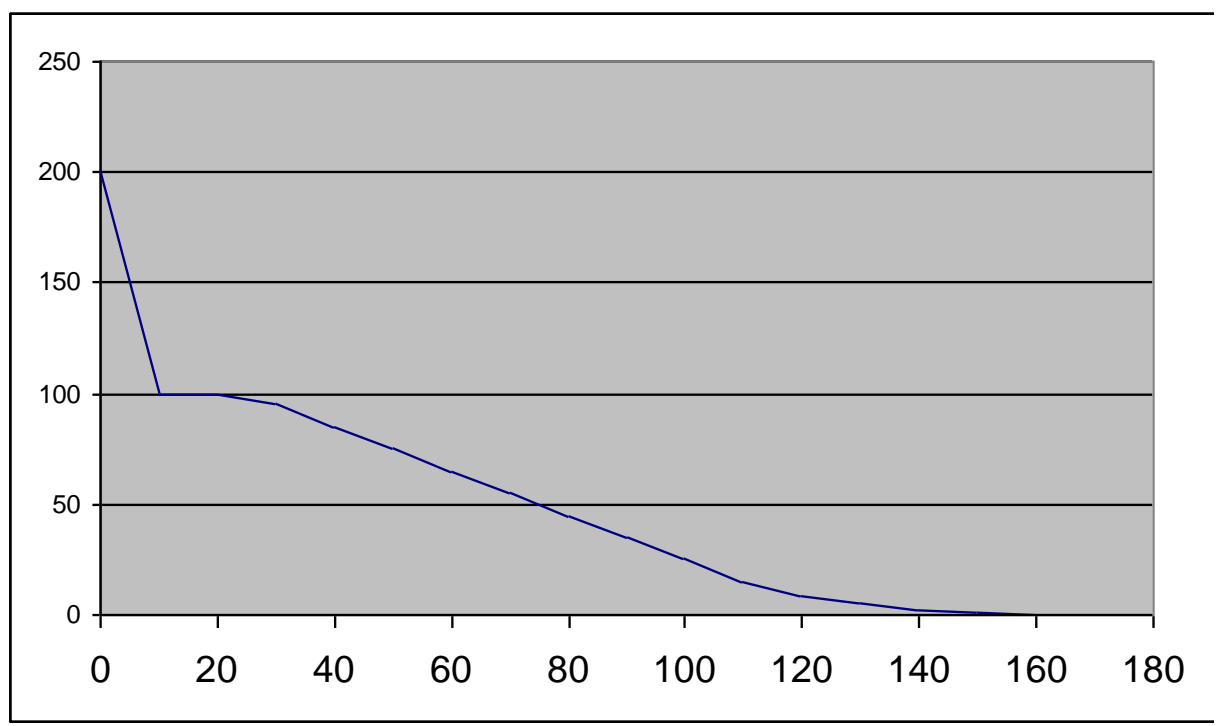

Figure (1): Standard solution curve prepared from standard solution

\section{Total Ionic strength adjusting buffer (TI-} $S A B)$ :

The TISAB was prepared by adding $500 \mathrm{ml}$ of deionized $\mathrm{H} 2 \mathrm{O}$ to $27 \mathrm{ml}$ of analyr reagent (AR)grade $\mathrm{NaCl}$, and 0.03 grams of sodium citrate. The solution was triturated to $\mathrm{PH}$ of 5.0-5.5 using (AR) grade $5 \mathrm{M} \mathrm{NaOH}$. The solution was cooled and then diluted to volume liter ${ }^{(15)}$.

\section{Fluoride measurement:}

Fluoride released was measured by using a radiometer with the fluoride ion selective electrode. The measuring unit is by milivolts $(\mathrm{mv})$. Then the reading from the device was pointed to the standard solution curve and according to the calibration curve method the reading was determined by the use of the regression equa- tion to obtain the concentration of the fluoride $^{(16)}$.

\section{RESULTS}

Measurements of fluoride ion released from the two typeas of materials. Tetric ceram and Kerr composite resin were made. The results were obtained in MV (mill volt) then these results where converted to PPM (part per million), A curve of fluoride release was drawn for each type of material. The result in Tables (1 and 2) showed ANOVA for the means amount of the fluoride released for the tested groups the result showed that there was a significant difference of the means among tested groups at $p \leq 0.0 .01$. 
Table (1) Mean and Standard deviation for the amount of fluoride released from Tetric composite resin.

\begin{tabular}{cccccc}
\hline Source of variance & Sum of Squares & df & Mean Square & F & Sig. \\
\hline Between Groups & 96987.554 & 6 & 16164.592 & 25.621 & .000 \\
Within Groups & 260566.689 & 413 & 630.912 & & \\
Total & 357554.243 & 419 & & & \\
\hline
\end{tabular}

Df: degree of freedom; Sig: Significancy.

Table (2) Mean and Standard deviation for the amount of fluoride released from Kerr composite resin.

\begin{tabular}{cccccc}
\hline Source of variance & Sum of Squares & df & Mean Square & F & Sig. \\
\hline Between Groups & 3876.460 & 6 & 646.077 & 21.039 & .000 \\
Within Groups & 26026.230 & 203 & 128.208 & & \\
Total & 29902.690 & 209 & & & \\
\hline
\end{tabular}

Df: degree of freedom; Sig: Significancy.

The amount of fluoride release in ppm for the observations days as shown in Figure
(2) for tetric ceram and Figure (3) for Kerr composite resin.

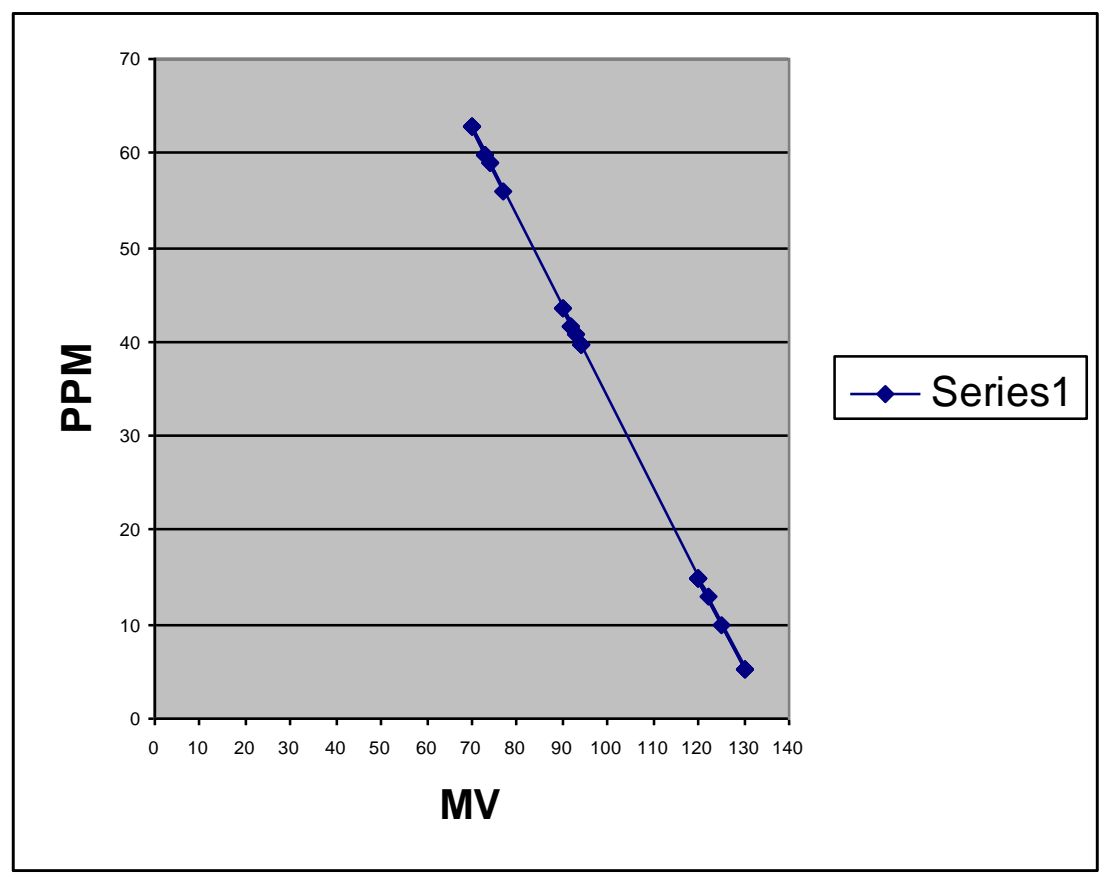

Figure (2): Fluoride released from Kerr in the first day 


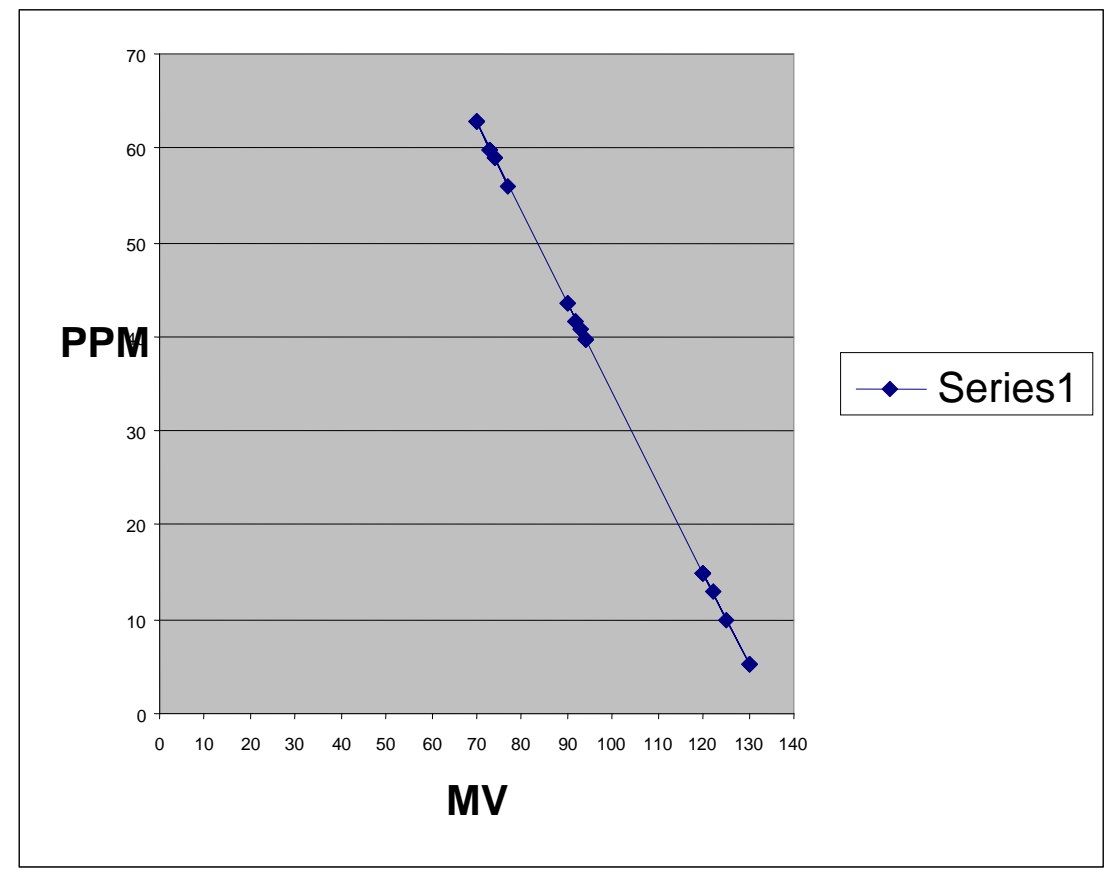

Figure (3): Fluoride released from kerr in the first day

\section{Tetric ceram:}

The amount of fluoride release from tetric ceram which cured at the high intensity $\left(400 \mathrm{Mv} / \mathrm{cm}^{2}\right)$ are less than the amount of fluoride release from the material that cured at the intensity of $\left(300 \mathrm{Mw} / \mathrm{cm}^{2}\right)$ while the amount of fluoride release from the materials cured at the intensity (170 $\mathrm{Mw} / \mathrm{cm}^{2}$ ) are more than the other previous samples which cured at higher intensity as shown in Table (1).

\section{Kerr composite resin:}

Also the same the amount of the fluoride release from the samples cured at the high intensity are less from the amount of the fluoride release of the materials cured at low intensity. The mean and standard deviation for the amount of fluoride release with different intensity of light cured Kerr composite are shown in Table(2).

\section{DISCUSSION}

Ytterbium fluoride is incorporated to render fluoride-releasing composite however fluoride is released in a small amounts. The silica glasses are covered with silane coupling agents, dysfunctional molecules which bond with silicas hydroxyl group in one end with the double bond of the monomer matrix in the other end ${ }^{(17)}$. This type of a double bond when curing most of the double bond $(-\mathrm{c}=\mathrm{c}-)$ change to a single bond $(\mathrm{c}-\mathrm{c})$ during poly merization. Exposure intensity and curing times of visible light are important factors in composite resin polymerization. Composite resin requires sufficient intensity of the light and suitable wave length with a dequate curing time for the activation responsible for initiating polymerization ${ }^{(18-}$ ${ }^{20)}$. There was significant difference in the degree of conversion of composite resin by the use of different light intensity. There is increasing in the degree of conversion by the increasing of the light intensity ${ }^{(18,19,20,21)}$. So the high degree of conversion will lead to conversion of double bond to a single bond $(-\mathrm{c}=\mathrm{c} 1)$ ( $\mathrm{c}-$ c). Thus will lead high polymerization degree as the intensity increase $400 \mathrm{Mw} / \mathrm{cm}^{2}$. There is increase of polymerization, the fluoride ion will trapped inside the lattice of polymer. So there is obstraction in the fluoride release by the increasing of the intensity of the light cure, the amount of fluoride release will decreased as shown in Figures (1 and 2). While when there is decrease in the imtemsity of light cure 170 
$\mathrm{mw} / \mathrm{cm} 2$ there is a high amount of fluoride release by the decrease of the intensity of light cure.

\section{CONCLUSIONS}

The amount of fluoride released from the composite resin which were cured by light cure were significantly different according to the differ of $170 \mathrm{Mw} / \mathrm{cm}^{2}$ light cure intensity. There is high amount of fluoride release with the low intensity light cured composite and there decrease in the amount of the fluoride release by the increase of the light cure intensity 400 $\mathrm{Mw} / \mathrm{cm}^{2}$.

\section{REFERENCES}

1. Toumba K J, Curzona MEJ. Slow release fluoride . Caries Res 27(suppl). 1993 :4346.

2. Castioni N V, Baehni PC,Gurny R. Curvent status in oral fluoride pharma cokinetics and implications for the prophylaxis against dental caries. Eurdpharm Biophara. 1998. 45:101-111.

3. Eichmiller F C, Marjenhoff WA. Fluoride releasing dental restoration materials.Oper Dent. 1998. 24:218-228.

4. Randall RC, Wilson NHF. Glass Inonmer systematic review of asecondary caries treatment effect. J Dent Res. 1999; 16:1066

5. Hareman CW, Summitt JB, Burgess JO. Carlson K. Three restoration materials and topical fluoride gel used in Xerostomic patients a clinical comparison. J A m Dent Assoc. 2003. 134:177-184.

6. Tingstad JE, Riegelmans. Dissolution rate studies I. Design and evaluation of a continuous flow apparatus. Jpharm Sci. 1970. 59:692-696.

7. Unos, Assussen E. Marginal adaptation of a restoration resin polymerized at reduced rate. Scand J Dent Res. 1999;99:440-4.

8. Leonard D, Charlton D, Hilton T. Effect of curing tip diameter on the accuracy of dental radiometers. Oper Dent. 1999; 24:31-7.

9. Vann Groeningen G, Jongebloedm W, Arends J. Composite resine after $1 \frac{1 / 2}{2}$ years of in vivo abrasion. An SEM inventigation Oper Dental. 1985; 16:253-8.

10. Lars en IB, Munksgaard E C. Effect of human saliva on surface degradation of composite resins. Scand. J. of Dent. Res. 1991; 99:254-61.

11. Miyazaki M, Oshida Y, Moore BK, Onose H. Effect of light exposure on fracture toughness and flexural strength of lightcured composite Dental materials. 1996; 12:28-332.

12. Lovell L G, Lult, Elliot J E, Stansbury JW, Bowman CN. The effect of cure rate on mechanical properties of dental resins. Dental Materials. 2001; 17:504-11.

13. Miyazaki M, Hattori T, Ichiishiy, Kondo M, Onose H, Moore K. Evaluation of curing units used in private dental affices. Oper Dent. 1998; 23:50-4.

14. Emami N, Soderholm KJM, Berglund LA. Effect of light power density variations on bulk curing properties of dental composites. J Dent. 2003; 31:189-96.

15. Moudy GJ and Thomas JDR (1981) Ion Selective electrodes in analytical chemistry, $2^{\text {nd }}$ eidition Henery Freizer, New York Chap. 10:369-370.

16. Martin S, Frant and James W Ross J (1968) Use of total ionic strength adjustment buffer determination of fluoride in water supplies. J Anal Cham 7:1169-1170.

17. Summelin (1981). Chemistry for the life sciences Dilution problems, $1^{\text {st }}$ edition R. H Inc. New York. Chap.

18. Daniel Fortin D.M.D., Marcos A. Vargas D.D.S. The spectrum of composites: New techniques and materials. J A m Dent Assoc. 2000. 131:265-306.

19. Sobrinho C., de Goes MF, Consani S. Sinhoreti MAC, Knowles JC(2000) Correlation between light intensity andexposure time on the hardness of composite resin. J Mater Sci: Mater Med 11:361.

20. Pradhan RD, Melikechi N, Eichmiller $\mathrm{E}(2002)$. The effect of irradiation wave length band with and spot size on the scraping depth and temperature rise in composite exposed to an argon laser or a conventional quartz tungsten halogen source . Dent Mater quartz. 18: 221-226.

21. Uhl A, Mills RW, Jandt KD (2003) polymerization heat of dental composite induced by Led and Halogen light curing units Biomaterials; 24:1809-1820.

22. Mu Sanje L, Darvell BW(2003) polymerization of resin composite restorative materials: exposure reciprocity. Dent Mater; 19:531-541. 